\title{
Experimental development process of similar material of water resisting layer in physical model test
}

\author{
Qi Liu ${ }^{1,2}$, Shaojie Chen ${ }^{1 *}$, Shuai Wang ${ }^{3,4}$, Jing Chai ${ }^{2}$, Dingding Zhang ${ }^{2}$, and Kailiang Yao $^{2}$ \\ ${ }^{1}$ Shandong University of Science and Technology, State Key Laboratory of Mining Disaster \\ Prevention and Control Co-founded by Shandong Provence and the Ministry of Science and \\ Technology, Qingdao 266590, China. \\ ${ }^{2}$ School of Energy and Mining Engineering, Xi' an University of Science and Technology, Xi'an \\ 710054, China. \\ ${ }^{3}$ China Coal Technology and Engineering Group Shenyang Research Institute, Fushun 113122, China. \\ ${ }^{4}$ State Key Laboratory of Coal Safety Technology, Fushun 113122, China.
}

\begin{abstract}
The stability evaluation of water resisting layer in the process of coal mining is the key to study the law of water and soil loss and prevent the loss of water resources. The development and proportioning of similar materials are the basis to study the stability of water resisting layer by physical simulation. A new type of similar material considering water characteristics was developed through orthogonal experiments. The similar material was composed of river sand, bentonite, silicone oil, vaseline, and water. Determine the best test development process. First of all, the proportion test scheme is designed based on the orthogonal test. Then, the influence of cement concentration, mass ratio of silicone oil to vaseline and other components on the density, uniaxial compressive strength, elastic model and Poisson's ratio of similar materials was analyzed by range analysis. Finally, the multiple linear regression equation between the parameters and the composition of similar materials for water resisting layer is obtained, and the optimal composition ratio is further determined according to the relationship between the test influencing factors and the mechanical properties of similar materials. The results show that the selected raw materials and their proportioning method are feasible. The content of river sand plays a major role in controlling the density and Poisson's ratio of similar materials. The mass ratio of aggregate to binder is the main factor affecting the uniaxial compressive strength and elastic modulus of similar materials, while the cementing concentration has the second largest influence on the density, uniaxial compressive strength, elastic modulus and Poisson's ratio of similar materials. Determining the cementing concentration that matches the design of similar material model tests is critical to improving test accuracy and provides a reference for the preparation of similar materials for water resisting layer under different requirements during the development of similar materials.
\end{abstract}

${ }^{*}$ Corresponding author: chensi@sdust.edu.cn 


\section{Introduction}

Theoretical derivation, numerical simulation and physical model test are three main research methods to solve complex engineering geological and geotechnical problems[1-5]. Based on the principle of similarity, the physical model can reflect the interaction relationship and mechanism of the actual geotechnical geological structure[6-11]. The main characteristics of the physical model experiment are the short period, and the result is intuitive and cost-effective. To achieve accurate physical model tests, similar materials must have similar physical and mechanical properties as the imitated objects[12-18]. Similar materials are composed of raw materials with different characteristics, and determining the proportion is an important method to simulate different real materials[19-24]. Therefore, the selection and proportion of raw materials have an important effect on the accuracy of physical model tests[25-31].

Physical model tests are widely used in underground coal mining, tunnel engineering and other underground engineering fields[32-38]. The main factors that affect the physical and mechanical properties of similar materials are the selection of raw materials (aggregate, cementitious material), proportion, density, moisture content, etc[39-44]. However, the research focus is on the selection of raw materials and their proportion, while there are few studies on the effect of the moisture content on the mechanical properties of similar materials[45-48]. Liu Shiliang et al.[49] developed new similar materials that satisfy the requirements of fluid-solid coupling using river sand, calcium carbonate, talc, white cement, petroleum jelly and anti-wear hydraulic oil as raw materials; they tested the mechanical properties of the samples and applied the research results to the physical model test of water inrush from the coal floor. Guo Guangli et al.[50,51] studied the time-varying characteristics of similar material strength through block experiments and proposed the methods to reduce the timevarying characteristics of the material strength and improve the simulation results. Wen caoxuan et al.[52] searched for similar materials that could simulate mudstone and explored the effect of each component of similar materials on its density, compressive strength, elastic modulus and tensile strength. A new type of similar material with adjustable mechanical properties was proposed to satisfy the requirements of similarity with mudstone for different parameters. Zhang Shizhong et al.[53] used the weakly cemented water layer as the research object and developed a weakly cemented water-resistant similar material with the uniaxial compressive strength and permeability coefficient of the material as the main indicators.

Although these similar materials have been used in geotechnical engineering and geological engineering, some problems remain[54-61]. As a coagulant, gypsum can simulate the mechanical strength of rock in a limited range, which is difficult to satisfy the requirements of deformation or mechanical strength of similar materials. The mechanical strength of similar materials is greatly affected by moisture, and most studies focus on the selection and ratio of materials, but there are few studies on the residual moisture content of similar materials during the drying process[62-68]. The effect of the combination of the ratio, density and residual water content of similar materials on their own physical and mechanical properties is relatively rare. In the existing research, the effect of the material composition ratio on the performance of similar materials is usually qualitatively analyzed, but there is a lack of quantitative methods to prepare similar materials under different requirements in physical model tests.

On this basis, first, the raw materials of similar materials, such as river sand, bentonite, silicone oil and vaseline, were selected according to the preparation requirements of similar materials. Secondly, the sample parameters such as density, compressive strength, elastic modulus and Poisson's ratio were tested. Thirdly, the properties of similar materials are quantitatively analyzed by range analysis, variance analysis and regression methods. Finally, the research results are applied to physical model tests of coal mining under geological conditions with water-bearing layers. 


\section{Similar Materials and Methods}

Similar theory and raw materials of similar materials are the basis of the optimal proportion of ingredients. The similarity principle of the physical model test indicates that the phenomenon reproduced in the physical model should be similar to the simulated object, i.e., according to the similarity principle, the geometric dimension, load, boundary condition, gravity, strength, deformation characteristics and water physical characteristics of the model should be similar to the simulated object. The similarity scale $\mathrm{C}$ is the ratio of physical quantities with the same dimension between prototype and model. According to the dimensional analysis method and basic equations of elasticity, the following similarity relations are obtained.

According to the dimensional analysis method, if the similar scale of physical quantity of the same dimension is equal, and the similar scale of dimension 1 is equal to 1 , then

$$
\begin{gathered}
C_{\mu}=C_{\varepsilon}=C_{\varphi}=1 \text { (1) } \\
C_{\sigma}=C_{\sigma_{c}}=C_{\sigma_{t}}=C_{E}=C_{c}
\end{gathered}
$$

where $C_{\mu}$ is the Poisson's ratio similarity ratio, $C_{\varepsilon}$ is the strain similarity ratio, $C_{\varphi}$ is the friction angle similarity ratio, $C_{\sigma}$ is the stress similarity ratio, $C_{\sigma_{c}}$ is the compressive strength similarity ratio, $C_{\sigma_{t}}$ is the tensile strength similarity ratio, $C_{E}$ is the elastic model similarity ratio, and $C_{c}$ is the cohesive force similarity ratio.

The similarity can be obtained from the equilibrium equation. The prototype equilibrium equation is

$$
\left(\sigma_{j i, j}\right)_{p}+\left(f_{i}\right)_{p}=0
$$

where $\left(\sigma_{j i, j}\right)_{p}$ is the prototype stress tensor, and $\left(f_{i}\right)_{p}$ is the prototype volume force tensor.

The equilibrium equation of the model is

$$
\left(\sigma_{j i, j}\right)_{m}+\left(f_{i}\right)_{m}=0
$$

where $\left(\sigma_{j i, j}\right)_{m}$ is the model stress tensor, and $\left(f_{i}\right)_{m}$ is the model volume force tensor.

According to the definition of similarity ratio, $C_{f}=\left(f_{i}\right)_{p} /\left(f_{i}\right)_{m}$, we substitute $C_{\sigma}, C_{L}$ and $C_{f}=C_{\gamma}$ into equation (3) to obtain

$$
\frac{C_{\sigma}}{C_{L}}\left(C_{j i, j}\right)_{m}+C_{\gamma}\left(f_{i}\right)_{m}=0(5)
$$

where $C_{L}$ is the geometric similarity ratio, $C_{f}$ is the volume force similarity ratio, and $C_{\gamma}$ is the severe similarity ratio.

According to equations (4) and (5), equation (6) can be obtained

$$
\frac{C_{L} C_{\gamma}}{C_{\sigma}}=1
$$


According to the geometric equations, physical equations, stress boundary conditions and displacement boundary conditions, the following relationship can be derived

$$
\frac{C_{\delta}}{C_{L} C_{\varepsilon}}=1 \text { (7) }
$$

$\frac{C_{\sigma}}{C_{E} C_{\varepsilon}}=1$ (8)

where $C_{\delta}$ is the geometric similarity ratio.

\subsection{Selection of Raw Materials}

River sand (China Xi'an Huizhong Construction Co., Ltd.) and bentonite (China Xi'an Jintianjiang Mining Co., Ltd.) were selected as aggregates of similar materials. Silicone oil (China Xi'an duoweiqiao chemical raw materials Co., Ltd.) and vaseline (China Xi'an Jinyuan Biotechnology Co., Ltd.) were selected as binders for similar materials, as shown in Figure 1.
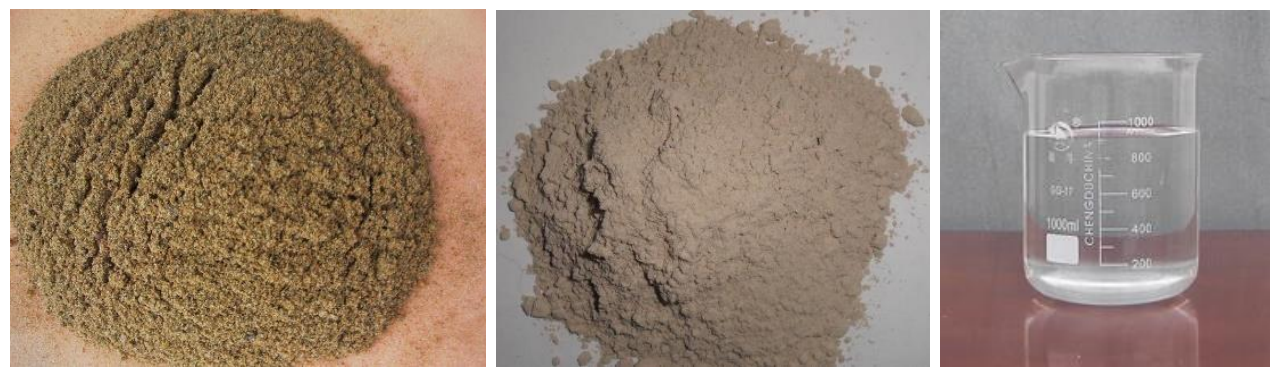

(a) (b) (c)

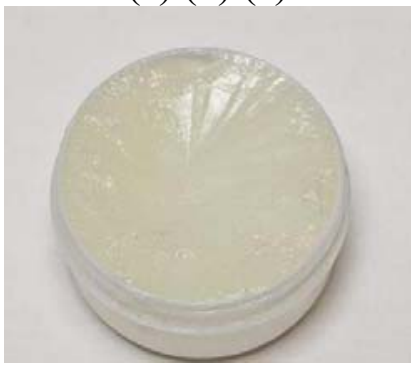

(d)

Fig. 1. Raw materials of the similar material: (a) river sand; (b) bentonite; (c) silicone oil; (d) vaseline.

(1) Aggregate: river sand, bentonite

The average particle size of river sand is $1.0-1.5 \mathrm{~mm}$, and the average particle size of bentonite is 1.1-1.7 $\mathrm{mm}$. Bentonite has the characteristics of low permeability, low diffusion, strong swelling, strong self-sealing and strong self-healing. In view of the high content of clay minerals in the water-repellent layer, it has strong ductility and hydraulicity, which can make the cracks formed by mining easy to close and produce water-repellent characteristics. The bentonite with low permeability and strong expansibility is selected as 
another component of the aggregate to realize the physical simulation of the deformation and water rationality of the water resisting layer.

(2) Coagulant: Silicone oil, vaseline

Silicone oil has high viscosity and good sealing property. Vaseline is characterized by good chemical inertness, good adhesion, lipophilicity and high density. Vaseline is very waterproof and difficult to mix with water. The whole process can be controlled by improving compressive strength, elastic modulus and cohesion.

\subsection{Proportioning Scheme}

The method is mainly composed of three parts: orthogonal test scheme of similar materials, sample manufacture, and test of the mechanical properties of the sample.

\subsubsection{Orthogonal test scheme of similar materials}

The orthogonal test method is based on the partial factor design method, which is used to study the proportion of similar materials. The test results are called indicators, and the parameters that may affect the test results are called factors. The specific state of each factor for comparison in experiments is called the level.

The orthogonal test design method proposed in this study can be divided into three steps:

Step 1: Determine the factors. Four factors were established, namely: A, cementing concentration; $\mathrm{B}$, mass ratio of aggregate to cement; $\mathrm{C}$, mass ratio of silicone oil to vaseline; $\mathrm{D}$, mass ratio of river sand to bentonite.

Step 2: Set the level for each factor. As shown in Table 1, five levels are set for each factor.

Table 1. Orthogonal test design level.

\begin{tabular}{ccccc}
\hline Level & $\mathrm{A}(\%)$ & $\mathrm{B}$ & $\mathrm{C}$ & $\mathrm{D}(\%)$ \\
\hline 1 & 0 & $4: 1$ & $3: 7$ & $1: 1$ \\
2 & 1 & $5: 1$ & $4: 6$ & $1: 2$ \\
3 & 2 & $6: 1$ & $5: 5$ & $1: 3$ \\
4 & 3 & $7: 1$ & $6: 4$ & $1: 4$ \\
5 & 4 & $8: 1$ & $7: 3$ & $1: 5$ \\
\hline
\end{tabular}

Step 3: Design the orthogonal test design scheme in MATLAB (MATLAB2016, MathWorks, Los Angeles, USA, 2016). The orthogonal test design scheme has 4 factors and 5 levels, which can be expressed as $\mathrm{L}_{25}\left(5^{4}\right)$. In the orthogonal experimental design module of MATLAB software, the level of each factor is set as an input, which generates the scheme as shown in Table 2.

Table 2. Orthogonal test schemes of similar materials.

\begin{tabular}{ccccc}
\hline $\begin{array}{c}\text { Test } \\
\text { number }\end{array}$ & $\mathrm{A}(\%)$ & $\mathrm{B}$ & $\mathrm{C}$ & $\mathrm{D}$ \\
\hline 1 & 0 & $4: 1$ & $3: 7$ & $1: 1$ \\
2 & 0 & $5: 1$ & $4: 6$ & $1: 2$ \\
\hline
\end{tabular}




\begin{tabular}{|c|c|c|c|c|}
\hline 3 & 0 & $6: 1$ & $5: 5$ & $1: 3$ \\
\hline 4 & 0 & $7: 1$ & $6: 4$ & $1: 4$ \\
\hline 5 & 0 & $8: 1$ & $7: 3$ & $1: 5$ \\
\hline 6 & 1 & $4: 1$ & $5: 5$ & $1: 2$ \\
\hline 7 & 1 & $5: 1$ & $6: 4$ & $1: 3$ \\
\hline 8 & 1 & $6: 1$ & $7: 3$ & $1: 4$ \\
\hline 9 & 1 & $7: 1$ & $3: 7$ & $1: 5$ \\
\hline 10 & 1 & $8: 1$ & $4: 6$ & $1: 1$ \\
\hline 11 & 2 & $4: 1$ & $7: 3$ & $1: 3$ \\
\hline 12 & 2 & $5: 1$ & $3: 7$ & $1: 4$ \\
\hline 13 & 2 & $6: 1$ & $4: 6$ & $1: 5$ \\
\hline 14 & 2 & $7: 1$ & $5: 5$ & $1: 1$ \\
\hline 15 & 2 & $8: 1$ & $6: 4$ & $1: 2$ \\
\hline 16 & 3 & $4: 1$ & $4: 6$ & $1: 4$ \\
\hline 17 & 3 & $5: 1$ & $5: 5$ & $1: 5$ \\
\hline 18 & 3 & $6: 1$ & $6: 4$ & $1: 1$ \\
\hline 19 & 3 & $7: 1$ & $7: 3$ & $1: 2$ \\
\hline 20 & 3 & $8: 1$ & $3: 7$ & $1: 3$ \\
\hline 21 & 4 & $4: 1$ & $6: 4$ & $1: 5$ \\
\hline 22 & 4 & $5: 1$ & $7: 3$ & $1: 1$ \\
\hline 23 & 4 & $6: 1$ & $3: 7$ & $1: 2$ \\
\hline 24 & 4 & $7: 1$ & $4: 6$ & $1: 3$ \\
\hline 25 & 4 & $8: 1$ & $5: 5$ & $1: 4$ \\
\hline
\end{tabular}

\subsubsection{Preparation of specimen}

(1) Material preparation. Prepare raw materials according to the dosage of river sand, bentonite, silicone oil and vaseline in Table 2.

(2) Design molds. Considering the difficulties in forming similar specimens with different moisture contents in the past, the specimen was redesigned and produced in this test. As shown in Figure 2, the size of the mold is $\Phi 50 \mathrm{~mm} \times 100 \mathrm{~mm}$, and 3 molds are required in the test.

(3) Mixing. Place the prepared raw materials in a mixing container and stir for approximately 3 minutes. After the dry materials are evenly mixed, gradually add the weighed water. Simultaneously, slowly stir to avoid the difference in initial moisture content of similar materials caused by water splashing. The process is controlled within 5 minutes to prevent the material from agglomerating and affecting the strength of the test piece. 


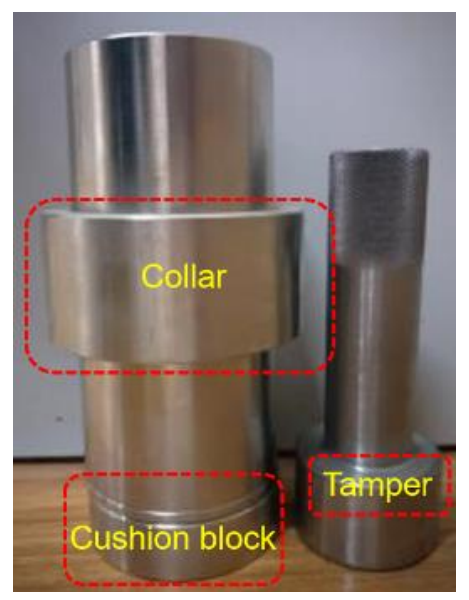

Fig. 2. New test mold.

(4) Filling. Put the mixed similar materials into three molds and fill them three times. Control the filling amount of each time to approximately $40 \%$ of the mold volume and compact them. Before each filling, the surface of the last tamping is scratched to prevent delamination of the test piece. After filling, the upper surface of the test piece is troweled with a small shovel to keep the end face of the upper surface flat.

(5) Demolding. Place the filled specimen mold at room temperature for 25 minutes. After molding, gently remove the mold collar, tap the outer surface of the mold with a hammer to loosen the specimen from the inner surface of the mold, and demold.

(6) Grouping. Each test number in Table 2 is a group; the number of test pieces in each group is 5 . Place the test pieces in a group form, number them in the form of $i j$, where $i$ is the test number in Table 2, $\mathrm{i}=1,2 \ldots 24,25$, and $\mathrm{j}$ is the number of the test piece in the group, $\mathrm{j}=1,2 \ldots 5$.

(7) Maintenance. To prevent the evaporation of water, wrap the demolded specimens with plastic wrap and place them in a light-tight sealed room. After all specimens are made, remove the plastic wrap. Place the test piece in the constant-temperature and -humidity box for curing, set the temperature in the box to $30^{\circ} \mathrm{C}$, take out the test piece every fixed time period for weighing and calculate the residual moisture content using equation (9). When the calculated residual moisture content value is close to the design value, the test can be performed.

$$
w=\frac{m_{1}-m_{0}}{m_{0}} \times 100 \%
$$

where $W$ is the moisture content, $m_{1}$ is the mass of the specimen to be tested, and $m_{0}$ is the mass of the specimen when it is completely dry.

\subsubsection{Specimen test index parameters}

Similar materials must satisfy the requirements of solid deformation and mechanical properties. Therefore, the index parameters of samples with the compressive strength, elastic modulus, and Poisson's ratio were tested. The MTS electronic universal testing machine (C43, MTS China Co., Ltd., Beijing, China) was used for uniaxial compression test, using displacement control, setting preload force of $10 \mathrm{~N}$, loading rate of $1 \mathrm{~mm} / \mathrm{min}$, sampling frequency of $2 \mathrm{~Hz}$. The test system is shown in Figure 3. 


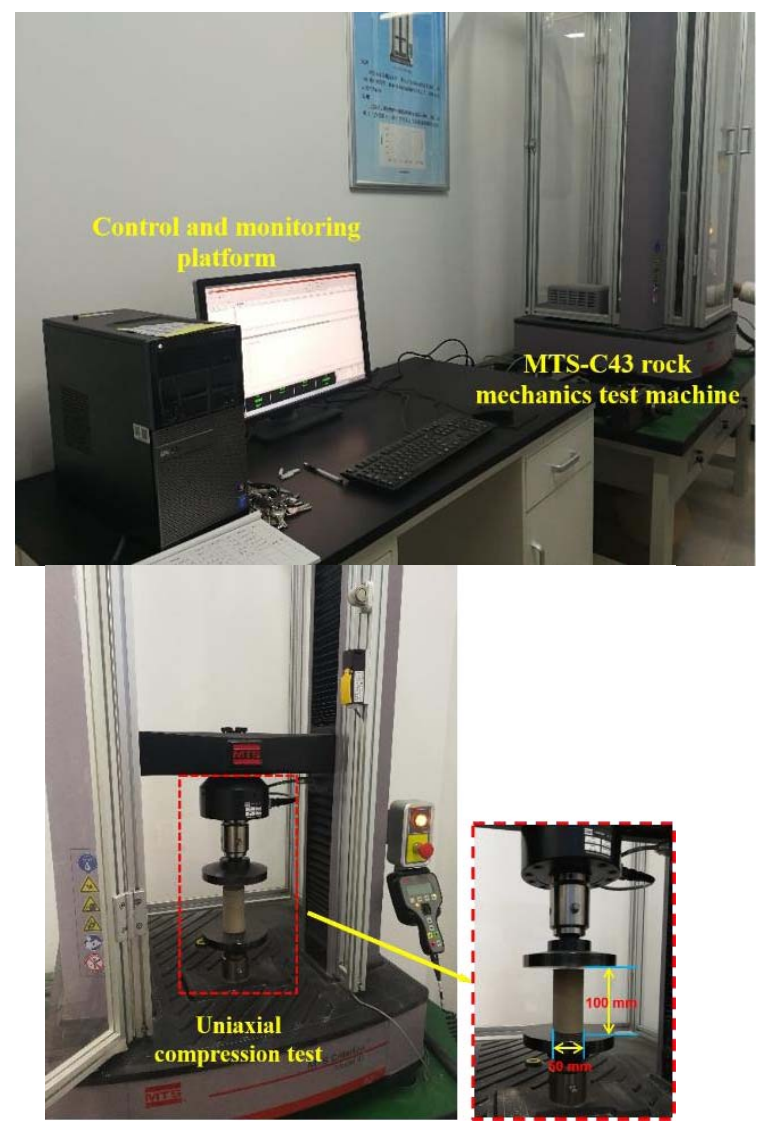

Fig. 3. Experimental system.

(1) Test compressive strength $\sigma_{c}$

The compressive strength is tested using an MTS electronic universal testing machine, which is calculated based on the stress-strain curve and the limit load calculation.

The calculation method of uniaxial compressive strength is as follows:

$$
\sigma_{c}=\frac{P}{A}(10)
$$

where $\sigma_{c}$ is the uniaxial compressive strength, $P$ is the ultimate load, and $A$ is the crosssectional area of the sample.

(2) Test elastic modulus

The elastic modulus of the test piece is obtained by fixing the resistance strain gauge on the test sample with special glue. When the rock sample is deformed by force, the resistance strain gauge is also deformed, so its resistance will change accordingly. Under the uniaxial compression state, the slope of the straight line on the stress and longitudinal strain curve drawn by one-time loading is the elastic model modulus.

$$
E_{t}=\frac{\Delta \sigma}{\Delta \varepsilon_{l}}(11)
$$

where $E_{t}$ is the elastic modulus, $\Delta \sigma$ is the change in longitudinal stress, and $\Delta \varepsilon_{l}$ is the change in longitudinal strain. 
(3) Measuring Poisson's ratio $\mu$

According to the ratio of the average transverse strain and average longitudinal strain of the corresponding straight section on the curve of stress vs. longitudinal strain curve and stress vs. lateral strain curve:

$$
\mu=\frac{\Delta \varepsilon_{d}}{\Delta \varepsilon_{l}}(12)
$$

where $\mu$ is Poisson's ratio, $\Delta \varepsilon_{d}$ is the change in lateral strain, and $\Delta \varepsilon_{l}$ is the change in longitudinal strain.

Table 3. Index parameters of the specimens.

\begin{tabular}{|c|c|c|c|c|}
\hline $\begin{array}{c}\text { Test } \\
\text { number }\end{array}$ & $\begin{array}{l}\text { Density } \\
\left(\mathrm{g} / \mathrm{cm}^{3}\right)\end{array}$ & $\begin{array}{l}\text { Compress } \\
\text { ive } \\
\text { strength } \\
\text { (MPa) }\end{array}$ & $\begin{array}{c}\text { Elastic } \\
\text { Modulus } \\
(\mathrm{MPa})\end{array}$ & $\begin{array}{c}\text { Poisson's } \\
\text { ratio }\end{array}$ \\
\hline 1 & 1.776 & 2.282 & 490.517 & 0.023 \\
\hline 2 & 1.949 & 2.143 & 480.781 & 0.052 \\
\hline 3 & 1.928 & 1.537 & 359.843 & 0.029 \\
\hline 4 & 2.020 & 1.595 & 378.409 & 0.112 \\
\hline 5 & 2.034 & 1.433 & 302.367 & 0.112 \\
\hline 6 & 1.991 & 2.432 & 493.903 & 0.065 \\
\hline 7 & 1.979 & 2.159 & 530.239 & 0.044 \\
\hline 8 & 1.964 & 1.635 & 385.929 & 0.126 \\
\hline 9 & 2.055 & 1.545 & 321.164 & 0.152 \\
\hline 10 & 1.862 & 1.016 & 184.935 & 0.041 \\
\hline 11 & 2.021 & 2.162 & 470.312 & 0.067 \\
\hline 12 & 1.972 & 1.921 & 377.933 & 0.161 \\
\hline 13 & 2.007 & 1.725 & 333.938 & 0.172 \\
\hline 14 & 1.846 & 1.478 & 266.047 & 0.060 \\
\hline 15 & 1.947 & 0.847 & 201.142 & 0.072 \\
\hline 16 & 2.044 & 1.462 & 326.799 & 0.154 \\
\hline 17 & 2.061 & 1.432 & 256.681 & 0.167 \\
\hline 18 & 1.931 & 1.021 & 191.870 & 0.079 \\
\hline 19 & 1.971 & 0.903 & 174.134 & 0.100 \\
\hline 20 & 1.933 & 0.672 & 98.672 & 0.123 \\
\hline 21 & 2.037 & 1.603 & 342.955 & 0.187 \\
\hline 22 & 1.914 & 1.363 & 294.142 & 0.086 \\
\hline
\end{tabular}




\begin{tabular}{lllll}
\hline 23 & 1.967 & 0.683 & 141.287 & 0.118 \\
24 & 1.991 & 0.627 & 119.130 & 0.131 \\
25 & 1.985 & 0.353 & 77.181 & 0.178 \\
\hline
\end{tabular}

Table 3 shows that when the residual water content changes between 0 and $4 \%$, the density distribution range of similar material specimens with different proportions is 1.776 $2.061 \mathrm{~g} / \mathrm{cm}^{3}$, the compressive strength distribution range is $0.353-2.432 \mathrm{MPa}$, the elastic modulus distribution range is $77.181-530.239 \mathrm{MPa}$, the Poisson's ratio distribution range is $0.023-0.187$, and the mechanical properties of similar materials widely change.

\section{Results and Discussion}

According to the measured values of sample parameters, the qualitative and quantitative relationship between the sample parameters and the proportion of similar materials was obtained. To obtain the best proportion of ingredients, a similar model test of mining engineering under certain geological conditions was used as a case for analysis, and four multivariate linear regression equations were calculated to provide the best proportion of ingredients.

We directly use statistical knowledge to analyze the test results. The range analysis method is used to analyze the effect of each factor on the mechanical parameters of similar materials under different levels. According to the orthogonal test design method in Table 1, the mechanical parameters of similar materials at the same level for each factor are averaged, and the difference between maximum and minimum values of each level is the range. The magnitude of the range reflects the effect of different factors on the mechanical properties of similar materials. A larger range corresponds to a greater difference in test results produced by different levels of this factor, which indicates its importance, and a more obvious effect on the test results. The following is an analysis of the sensitivity of various factors using range analysis.

\subsection{Results}

Through range and variance analysis, the relationship between the sample index parameters (density, compressive strength, elastic modulus and Poisson's ratio) and the four factors in the orthogonal test program were quantitatively and qualitatively analyzed. The variance analysis was performed using MATLAB (MATLAB 2016, MATLAB information technology Co., Ltd., Los Angeles, 2016).

Density analysis

The sample density analysis is as follows: First, the qualitative analysis is studied through range analysis; in addition, the quantitative analysis is performed through analysis of variance to obtain the quantitative relationship between the sample density and the four factors.

The average value and range of the factors affecting the density of the test piece at different levels are calculated, as shown in Table 4. Among them, the range value of mass ratio of river sand to bentonite is the largest, which is far greater than the range value of cementing concentration, mass ratio of silicone oil to vaseline and mass ratio of aggregate to cement. This shows that mass ratio of river sand to bentonite has an obvious control on the density of similar materials, and cementing concentration and mass ratio of silicone oil 
to vaseline also have a certain impact, while the mass ratio of aggregate to cement has the smallest impact. The results show that the sensitivity of each factor to the density of similar materials is in the order of mass ratio of river sand to bentonite, cementing concentration, mass ratio of silicone oil to vaseline and mass ratio of aggregate to cement. In Table 4, it can be seen that $R_{D}>R_{A}>R_{C}>R_{B}$. Therefore, the order of factors affecting the sample density is $\mathrm{D}>\mathrm{A}>\mathrm{C}>\mathrm{B}$.

Table 4. Range analysis of the density of similar materials

\begin{tabular}{ccccc}
\hline \multirow{2}{*}{ Level } & \multicolumn{4}{c}{ Mean density of different factors $\left(\mathrm{g} / \mathrm{cm}^{3}\right)$} \\
\cline { 2 - 5 } & $\mathrm{A}(\%)$ & $\mathrm{B}$ & $\mathrm{C}$ & $\mathrm{D}$ \\
\hline 1 & 1.915 & 1.907 & 1.890 & 1.915 \\
2 & 1.920 & 1.906 & 1.917 & 1.920 \\
3 & 1.970 & 1.905 & 1.914 & 1.970 \\
4 & 1.995 & 1.907 & 1.914 & 1.995 \\
5 & 1.967 & 1.908 & 1.909 & 1.967 \\
Range & 0.042 & 0.007 & 0.023 & 0.042 \\
\hline
\end{tabular}

Figure 4 shows a visual analysis of the effective factors affecting the density of the sample. It can be seen from the figure that the density of similar materials increases with the increase of mass ratio of river sand to bentonite, cementing concentration and mass ratio of silicone oil to vaseline, and slowly decreases with the increase of the ratio of mastic.
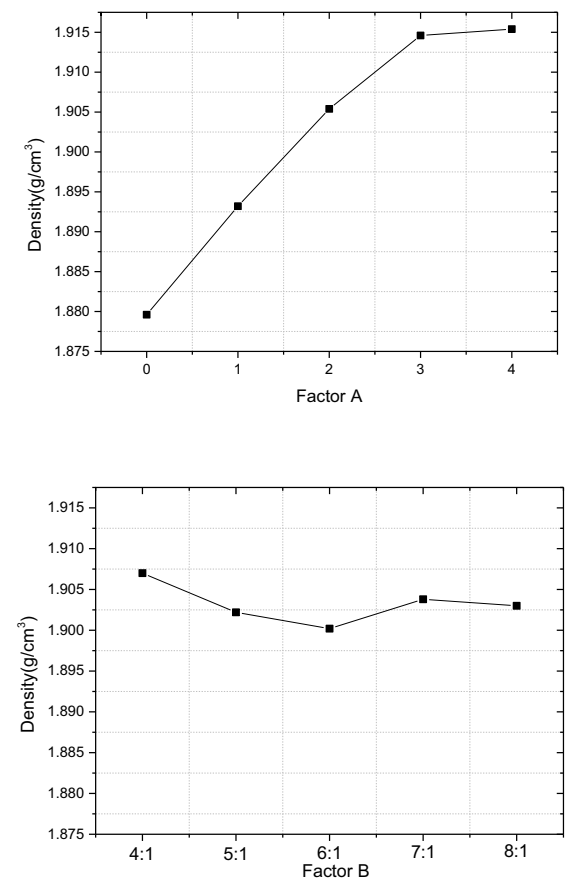

(a)

(b) 

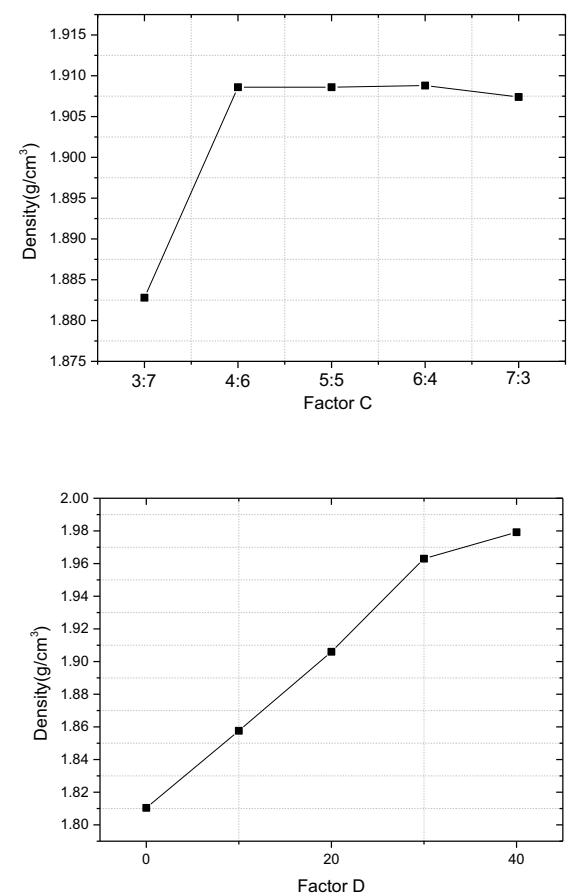

(c)

(d)

Fig. 4. Intuitive analysis chart of density influencing factors: (a) factor A; (b) factor B; (c) factor C; (d) factor D

\section{Compressive strength analysis}

The compressive strength analysis method is similar to the sample density. The average and range of each level of each factor affecting the uniaxial compressive strength in the orthogonal test results are shown in Table 5. It can be seen from the table that the range of mass ratio of aggregate to cement is the largest, followed by cementing concentration, then mass ratio of river sand to bentonite, and mass ratio of silicone oil to vaseline is the smallest. This shows that the mass ratio of aggregate to cement plays a significant role in controlling the uniaxial compressive strength of similar materials, the cementing concentration has a greater impact, the mass ratio of river sand to bentonite has a certain impact, and the mass ratio of silicone oil to vaseline has the least impact. The sensitivity of each factor to the uniaxial compressive strength of similar materials is in the order of mass ratio of aggregate to cement, cementing concentration, mass ratio of river sand to bentonite and mass ratio of silicone oil to vaseline. In Table 5, it can be seen that $R_{B}>R_{A}>R_{D}>R_{C}$. Therefore, the order of factors affecting sample density is $B>A>D>C$.

Table 5. Range analysis of uniaxial compressive strength

\begin{tabular}{ccccc}
\hline \multirow{2}{*}{ level } & \multicolumn{4}{c}{$\begin{array}{c}\text { Average value of uniaxial compressive } \\
\text { strength of different factors }\end{array}$} \\
\cline { 2 - 5 } & $\mathrm{A}(\%)$ & $\mathrm{B}$ & $\mathrm{C}$ & $\mathrm{D}(\%)$ \\
\hline 1 & 1.857 & 2.044 & 1.307 & 1.857 \\
2 & 1.703 & 1.776 & 1.310 & 1.703 \\
\hline
\end{tabular}




\begin{tabular}{ccccc}
\hline 3 & 1.590 & 1.292 & 1.321 & 1.590 \\
4 & 1.041 & 1.211 & 1.349 & 1.041 \\
5 & 0.930 & 0.894 & 1.358 & 0.930 \\
Range & 0.932 & 1.243 & 0.053 & 0.932 \\
\hline
\end{tabular}

The sensitivity analysis curve between uniaxial compressive strength and various factors is shown in Figure 5. It can be seen from the figure that the uniaxial compressive strength of similar materials decreases with the increase of the mass ratio of aggregate to cement and cementing concentration, increases slowly with the increase of the mass ratio of river sand to bentonite, and the mass ratio of silicone oil to vaseline has little effect on the uniaxial compressive strength of similar materials.
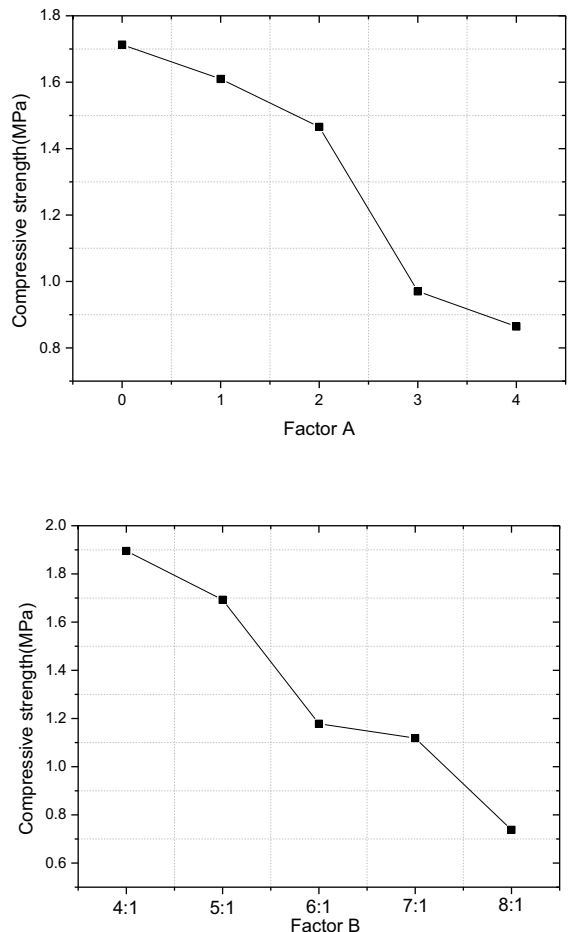

(a)

(b) 

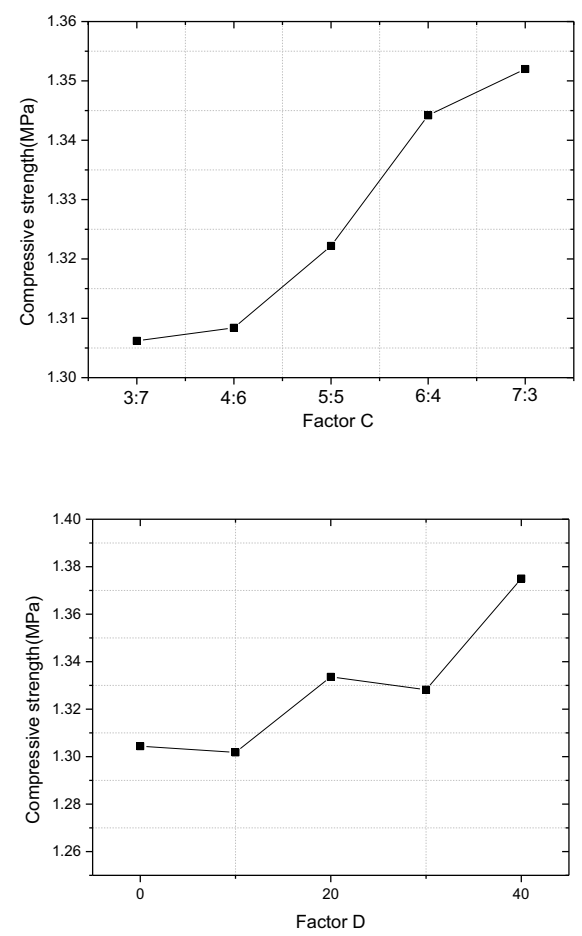

(c)

(d)

Fig. 5. Intuitive analysis chart of compressive strength influencing factors: (a) factor A; (b) factor B; (c) factor C; (d) factor D

Elastic modulus analysis

The average and range of each level of each factor affecting the elastic modulus in the orthogonal test results are shown in Table 6. It can be seen from the table that the range value of the mass ratio of aggregate to cement is the largest, followed by the cementing concentration, and the mass ratio of river sand to bentonite and the mass ratio of silicone oil to vaseline is smaller and close. This shows that the mass ratio of aggregate to cement plays an obvious role in controlling the elastic modulus of specimens of similar materials, the cementing concentration has a greater influence, and the effects of mass ratio of river sand to bentonite and the mass ratio of silicone oil to vaseline on the specimens are closer. The sensitivities of various factors to the elastic modulus of similar materials from large to small are in order of the mass ratio of aggregate to cement, cementing concentration, the mass ratio of silicone oil to vaseline and the mass ratio of river sand to bentonite. In Table 6 , it can be seen that $R_{B}>R_{A}>R_{C}>R_{D}$. Therefore, the order of factors affecting the sample density is $\mathrm{B}>\mathrm{A}>\mathrm{C}>\mathrm{D}$.

Table 6. Range analysis of elastic modulus

\begin{tabular}{ccccc}
\hline \multirow{2}{*}{ level } & \multicolumn{4}{c}{ Mean value of elastic modulus of different } \\
& \multicolumn{4}{c}{ factors (MPa) } \\
\cline { 2 - 5 } & $\mathrm{A}(\%)$ & $\mathrm{B}$ & $\mathrm{C}$ & $\mathrm{D}$ \\
\hline 1 & 398.40 & 431.85 & 279.77 & 277.00 \\
2 & 381.70 & 383.15 & 289.97 & 289.80 \\
3 & 324.56 & 271.21 & 282.68 & 307.22 \\
4 & 201.24 & 252.56 & 329.15 & 308.85 \\
\hline
\end{tabular}




\begin{tabular}{ccccc}
\hline 5 & 187.79 & 165.48 & 322.91 & 309.25 \\
Range & 220.54 & 280.50 & 56.57 & 28.99 \\
\hline
\end{tabular}

The sensitivity analysis curve between the elastic modulus and various factors is shown in Figure 6. The elastic modulus of similar materials decreases with the increase in mass ratio of aggregate to cement and residual water content and slowly increases with the increase in mass ratio of cement to gypsum. The effect of the barite powder content on the elastic modulus of similar materials is not obvious.
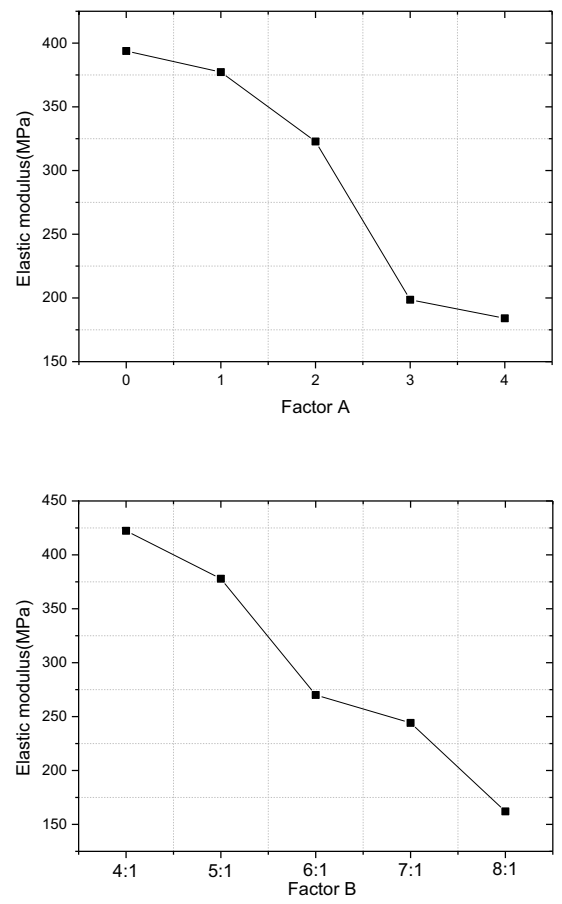

(a) (b) 

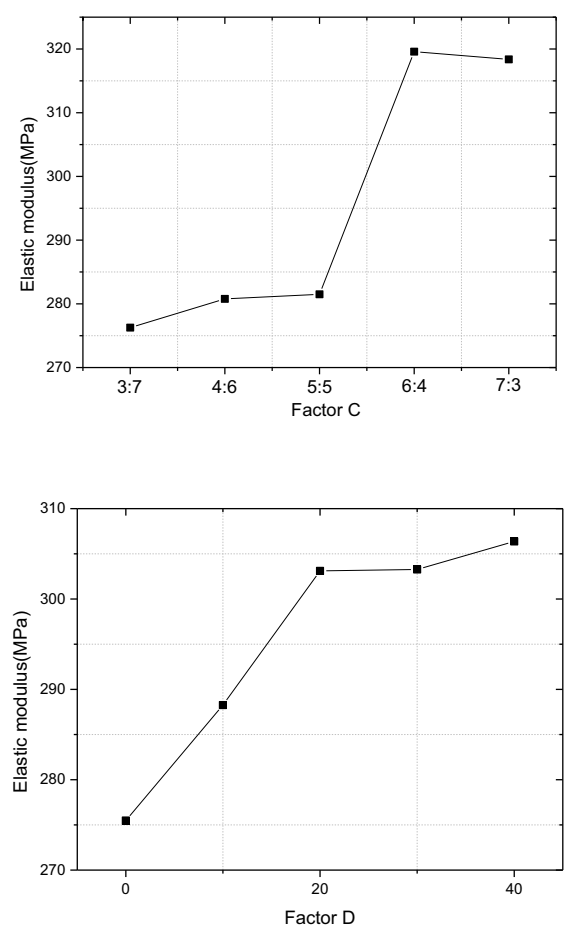

(c) (d)

Fig. 6. Intuitive analysis chart of the elastic modulus influencing factors: (a) factor A; (b) factor B; (c) factor $\mathrm{C}$; (d) factor D

\section{Poisson's ratio analysis}

The average and range of each level of each influencing factor of Poisson's ratio in the orthogonal test results are shown in Table 7. It can be seen from the table that the range of mass ratio of river sand to bentonite is the largest, followed by the cementing concentration, the range of the mass ratio of silicone oil to gypsum is smaller, and the range of the mass ratio of river sand to bentonite is the smallest. This shows that the mass ratio of river sand to bentonite has a significant effect on the Poisson's ratio of similar materials, the cementing concentration has a significant impact, the mass ratio of silicone oil to vaseline has a small impact on the Poisson's ratio, and the mass ratio of aggregate to cement has the least impact on the Poisson's ratio. The sensitivity of each factor to the Poisson's ratio of similar materials is from large to small in order of the mass ratio of river sand to bentonite, cementing concentration, mass ratio of silicone oil to vaseline, and mass ratio of aggregate to cement. In Table 7, it can be seen that $R_{D}>R_{A}>R_{C}>R_{B}$. Therefore, the order of factors that affect the sample density is $\mathrm{D}>\mathrm{A}>\mathrm{C}>\mathrm{B}$.

Table 7. The range analysis of Poisson ratio.

\begin{tabular}{ccccc}
\hline \multirow{2}{*}{ level } & \multicolumn{4}{c}{ Mean Poisson's ratio of different factors } \\
\cline { 2 - 5 } & $\mathrm{A}(\%)$ & $\mathrm{B}$ & $\mathrm{C}$ & $\mathrm{D}$ \\
\hline 1 & 0.139 & 0.099 & 0.110 & 0.079 \\
2 & 0.113 & 0.118 & 0.154 & 0.108 \\
\hline
\end{tabular}




\begin{tabular}{ccccc}
\hline 3 & 0.158 & 0.118 & 0.105 & 0.118 \\
4 & 0.212 & 0.107 & 0.133 & 0.155 \\
5 & 0.171 & 0.108 & 0.109 & 0.195 \\
Range & 0.083 & 0.007 & 0.018 & 0.102 \\
\hline
\end{tabular}

The sensitivity analysis curve between Poisson's ratio and each factor is shown in Figure 7. It can be seen from the figure that Poisson's ratio of similar materials increases rapidly with the increase of mass ratio of river sand to bentonite and cementing concentration, and decreases slowly with the increase of mass ratio of silicone oil to vaseline, while the influence of mass ratio of aggregate to cement on Poisson's ratio of similar materials is not obvious.

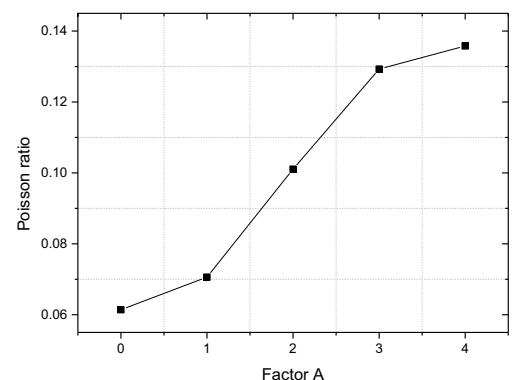

(a)

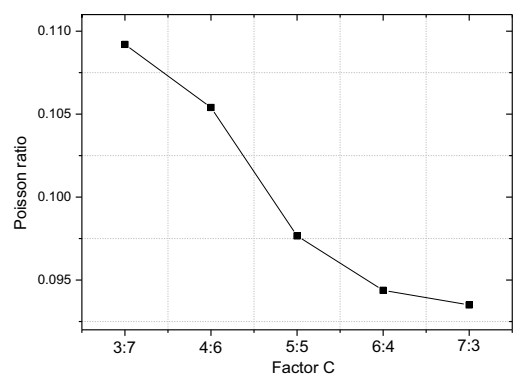

(c)

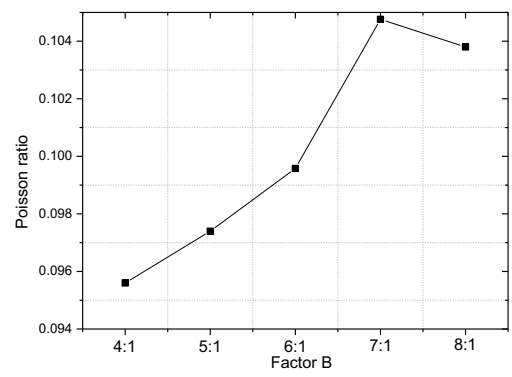

(b)

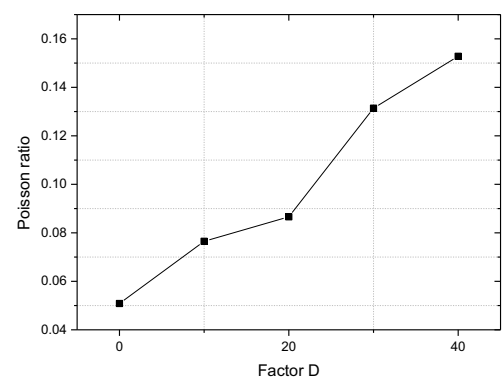

(d)

Fig. 7. Intuitive analysis chart of Poisson ratio influencing factors: (a) factor A; (b) factor B; (c) factor C; (d) factor D

Multiple regression analysis

According to the results of the orthogonal test in this paper, the sensitivity analysis chart of the factors and mechanical properties of similar materials shows that a good linear relationship between the factors and the mechanical properties of the specimen in the orthogonal test. Thus, the multiple linear regression analysis is performed. It is defined that the content of barite powder is $X_{1}$, the mass ratio of aggregate to cement is $X_{2}$, the mass ratio of cement to gypsum is $X_{3}$, and the residual moisture content is $X_{4}$. The density of similar material specimens is $Y_{1}$, the uniaxial compressive strength is $Y_{2}$, the elastic modulus is $Y_{3}$, and the Poisson ratio is $Y_{4}$. MATLAB software is used to analyze the mechanical properties of similar materials. Regression equation (13) is obtained. 


$$
\begin{aligned}
Y_{1}= & 0.005 X_{1}-0.0006 X_{2}+0.008 X_{3} \\
& +0.008 X_{4}+1.76 \\
Y_{2}= & 0.0028 X_{1}-0.289 X_{2}+0.027 X_{3} \\
& -0.23 X_{4}+3.54 \\
Y_{3}= & 0.773 X_{1}-65.43 X_{2}+25.62 X_{3} \\
& -59.82 X_{4}+759.79 \\
Y_{4}= & 0.002 X_{1}+0.0019 X_{2}-0.009 X_{3} \\
& +0.0187 X_{4}+0.0082
\end{aligned}
$$

Equation (13) can be used to calculate the density, uniaxial compressive strength, elastic modulus and Poisson's ratio of similar materials using mass ratio of river sand to bentonite, mass ratio of aggregate to cement, mass ratio of silicone oil to vaseline and cementing concentration. Generally, in the physical model test, according to the engineering geological data and similar theory, the design mechanical parameters of similar materials can be calculated. By solving equation (13), equation (14) can be obtained

$$
\begin{aligned}
X_{1}= & 164.6 Y_{1}-9.29 Y_{2}+0.05 Y_{3} \\
& +90.98 Y_{4}-279.58 \\
X_{2}= & 6.997 Y_{1}-2.95 Y_{2}+0.01 Y_{3} \\
& -13.56 Y_{4}-2.92 \\
X_{3}= & 0.09 Y_{1}-3.71 Y_{2}+0.018 Y_{3} \\
& -0.59 Y_{4}+1.37 \\
X_{4}= & -8.47 Y_{1}+0.72 Y_{2}-0.008 Y_{3} \\
& +20.3 Y_{4}+17.45
\end{aligned}
$$

When the density, uniaxial compressive strength, elastic modulus and Poisson's ratio of similar materials are determined, the mass ratio of river sand to bentonite, mass ratio of aggregate to cement, mass ratio of silicone oil to vaseline and cementing concentration in similar materials can be calculated by equation (14)

\subsection{Discussion}

The influence of aquifer on coal mining is a typical problem in geotechnical engineering. In order to explore the impact of aquifers on coal mining, a coal mine is taken as an example. The Yushenfu mining area is located at the junction of Inner Mongolia and Shaanxi. The Quaternary upper Pleistocene Salawusu formation aquifer distributed in this area is the water source for residents' living and industrial water. The burial depth of the sand-based coal seam in this area is generally about $100 \mathrm{~m}$, and coal mining will directly affect the water-bearing layer of the Sarawusu Formation. The structure in the area is simple, the formation dip angle is gentle, and no large fractures and folds are found. Judging from the trend reflected by the shape of the coal floor, it is basically a gently inclined near-horizontal structure, and it exhibits a wide undulation. In addition, the water in each layer of the mine is relatively rich. The main water damage in mining is from the clastic rock fissure confined aquifer.

The main water-bearing layer is from the top of bedrock to the top of 2-2 coal seam. In order to find out the interaction mechanism between the two coal seams and improve the reliability and safety of the surrounding rock support of the mine roadway, the influence of water content on the mechanical properties of the rock must be fully considered. Based on 
this, the research group used the method of similar material model test to study the law of spatiotemporal evolution of stress and strain during coal mining in the mine. Because the thickness of the strata between the two layers of coal is small, it is difficult to simulate the strata between the two layers of coal, and higher requirements are put forward for the accuracy of simulation test of similar materials. It is difficult to accurately control the mechanical properties of similar materials by using the traditional empirical method. In this paper, the proportion determination method of similar materials is introduced.

According to the similarity theory and prototype rock formation parameters, as shown in Table 8, the geometric similarity ratio of the simulation test of similar materials is selected as 1:50, i.e., $C_{l}=50$, the similarity ratio of bulk density is $C_{\gamma}=1.56$, the similarity ratio of stress and elastic modulus is $C_{\sigma}=C_{E}=1.56 \times 50=82.5$, the similar ratio of Poisson's ratio is $C_{v}=1$, and the experimental model parameters are calculated.

According to the physical and mechanical parameters of similar materials in Table 8, the density is $Y_{1}=1.712 \mathrm{~g} / \mathrm{cm}^{3}$, the uniaxial compressive strength is $Y_{2}=0.51 \mathrm{MPa}$, the elastic modulus is $Y_{3}=270.4 \mathrm{MPa}$, and Poisson 's ratio is $Y_{4}=0.21$ in equation (14). Here, $X_{1}=9.12$, $X_{2}=5.76, X_{3}=3.77$, and $X_{4}=5.23$. According to the preparation proportion of similar materials obtained by equation (14), the density, compressive strength, modulus of elasticity and Poisson's ratio of similar materials are obtained through the uniaxial compression test.

In the process of coal mining, there is incongruous deformation between the strata, and the tensile and shear composite failure of the coal rock body forms the separation layer and various crack distributions. The stability of the water-resisting layer and the dynamic evolution characteristics of the fractures in coal mining are studied by physical model experiment. As shown in Figure 8, during the mining process, the separated layer fracture development area is formed in the rock layer above the working face, which is consistent with the data obtained from the field measurement of the project. The physical model experiment reproduces the real situation of the site, and verifies that the similar materials of the water resisting layer play an effective role in the physical model experiment.

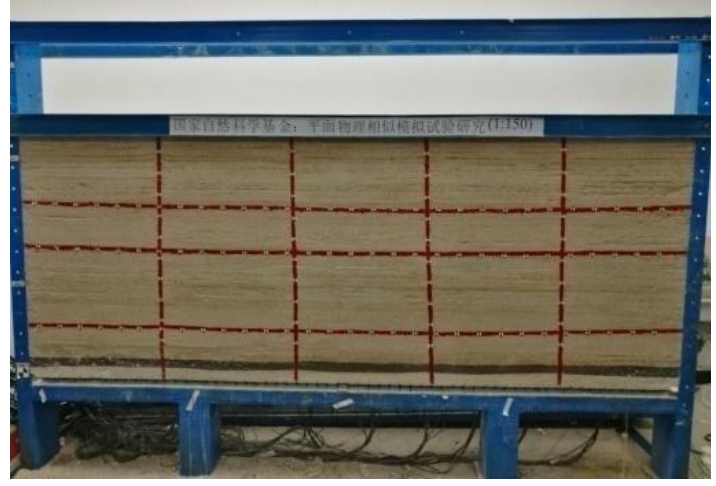




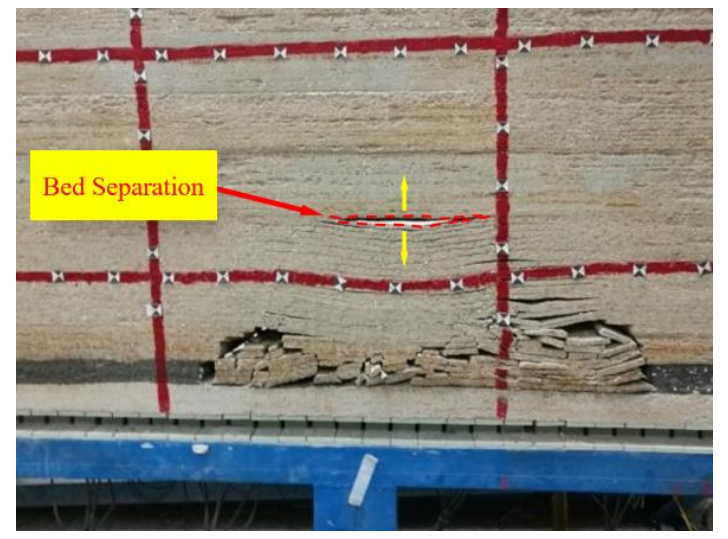

Fig. 8. Physical model experiment of coal mining with water-resisting layer. (a) Before mining (b) After mining

The difference between the calculated value and the test value of the mechanical parameters of similar materials should not exceed $20 \%$ as a criterion to determine whether the fitting effect of the regression equation is accurate. In this test, the relative error between calculated and measured mechanical parameters of similar materials is 7.12$14.73 \%$, which is less than $20 \%$. Therefore, the regression equation obtained in this test can effectively calculate the proportion of similar materials in the allowable error range of the project and improve the accuracy of the similar material model test. In addition, the physical model test was performed using the optimal moisture content, and the results were consistent with the actual mining, which proves that the new similar materials are feasible in solving mining and geotechnical problems.

Table 8. Comparison between calculated and measured mechanical parameters of similar materials

\begin{tabular}{ccccc}
\hline & $\begin{array}{c}\text { Density }(\mathrm{g} / \mathrm{c} \\
\left.\mathrm{m}^{3}\right)\end{array}$ & $\begin{array}{c}\text { Compressive } \\
\text { strength }(\mathrm{MPa})\end{array}$ & $\begin{array}{c}\text { Elasticity modulus } \\
(\mathrm{MPa})\end{array}$ & $\begin{array}{c}\text { Poisson's } \\
\text { ratio }\end{array}$ \\
\hline $\begin{array}{c}\text { Calculated values of } \\
\text { mechanical } \\
\text { parameters of } \\
\text { similar materials }\end{array}$ & 1.74 & 1.36 & 274.04 & 0.29 \\
$\begin{array}{c}\text { Measured values of } \\
\text { mechanical } \\
\text { parameters of }\end{array}$ & 1.87 & 0.90 & & \\
similar materials & & & & \\
Error $(\%)$ & 7.12 & 14.73 & & \\
& & & & \\
\hline
\end{tabular}




\section{Conclusions}

Based on the orthogonal test, a new development process of similar materials is established, in which river sand and bentonite are used as aggregate and silicone oil and vaseline are used as coagulant. Based on the orthogonal test, the proportion test scheme is designed. Prepare specimens to obtain parameters such as density, compressive strength, modulus of elasticity, and Poisson's ratio. The qualitative and quantitative relationship between the mechanical parameters of samples and the proportion of similar materials is obtained by range and variance analysis. The content of river sand is the main factor affecting the density and Poisson's ratio of similar materials. The mass ratio of aggregate to binder is the main factor affecting the uniaxial compressive strength and elastic modulus of similar materials. while the cementing concentration is the secondary factor that affects the density, uniaxial compressive strength, modulus of elasticity and Poisson's ratio of similar materials. The multiple linear regression equation between the mechanical parameters of the sample and the components of the similar material is obtained, and the optimum proportion of the components is further determined according to different requirements. Taking the geological conditions of Yushuwan coal mine as an example to carry out the similar model test, according to the multiple linear regression equation, the optimal ratio of river sand, the mass ratio of aggregate to binder, the mass ratio of silicone oil to vaseline and the mass ratio of river sand to bentonite was determined. The simulation test of similar materials was carried out. The maximum error of the test results and theoretical calculations was $14.73 \%$, which met the error requirements of the similar material model test, and could provide a reference for the proportion of similar material under different requirements.

\section{Acknowledgments}

This work was supported by the National Natural Science Foundation of China (NSFC, No. 51904168, 51804244), SDUST Research Fund (2019TDJH101), China Coal Technology and Engineering Group Co., Ltd. Science and Technology Innovation and Entrepreneurship Fund Special Project-Youth Project (2018-2-

QN012), and Social Development and Industrialization Guidance Plan in Liao Ning provinc e(2019JH8/10300099). The authors sincerely appreciate the financial supports of NSFC and the Chinese Ministry of Education. And thanks to the graduated students of Xi' an University of Science and Technology, this study would not to be so smooth implementation without them.

\section{References}

1. Gong W., Peng Y., He M., Wang J., TUNN UNDERGR SP TECH, 49, 156 (2015)

2. Zhao J., Yin L., Guo W., ROCK MECH ROCK ENG, 51:8, 2355 (2018)

3. Liu Y., Li W., He J., Liu S., Cai L., Cheng G., INT J ROCK MECH MIN, 106, 133 (2018) 
4. Song D., Che A., Zhu R., Ge X., LANDSLIDES., 15:6, 1109 (2018)

5. Wang X., Wen Z., Jiang Y., Huang H., ROCK MECH ROCK ENG, 51:3, 729 (2018)

6. Kong B., Wang E., Lu W., Li Z., ENERGY, 189, 116144 (2019)

7. Han W., Li G., Sun Z., Luan H., Liu C., Wu X., Symmetry, 12:2, 252 (2020)

8. Wang G., Liu Y., Xu J., SCI ENG, 8:3, 592 (2020)

9. Song D., Che A., Chen Z., Ge X., ENG GEOL, 245, 153 (2020)

10. Jiang L, Kong P, Zhang P, Shu J, Wang Q, Chen L, et al. ROCK MECH ROCK ENG, 53:4, $1737(2020)$

11. Li B., Li M., Gao W., Bi M., Ma L., Qin Q., et al. FUEL, 260, 116269 (2020)

12. Cui F., Zhang T., Lai X., Cao J., Shan P., ENERGIES, 12:23, 4513 (2019)

13. Zang C., Chen M., Zhang G., Wang K., Gu D., Research on the failure process and stability control technology in a deep roadway: Numerical simulation and field test. ENERGY SCI ENG (2020)

14. Zhang G., Chen L., Wen Z., Chen M., Tao G., Li Y., et al. Squeezing failure behavior of roof-coal masses in a gob-side entry driven under unstable overlying strata, ENERGY SCI ENG (2020)

15. Guo W.Y., Yu F.H., Tan Y.L., Zhao T.B., Experimental study on the failure mechanism of layer-crack structure. ENERGY SCI ENG, 7(6) 2351 (2019)

16. Song D., Che A., Zhu R., Ge X., ROCK MECH ROCK ENG, 52:11, 4457 (2019)

17. Sun H., Liu X.L., Zhu J.B., INT J ROCK MECH MIN, 117, 1 (2019)

18. Guo W., Gu Q., Tan Y., Hu S., ENERGIES. 12, 13307 (2019)

19. Chen S., Du Z., Zhang Z., Zhang H., Xia Z., Feng F., Effects of chloride on the early mechanical properties and microstructure of gangue-cemented paste backfill. CONSTR BUILD MATER, 235,117504 (2020)

20. Chen S., Du Z., Zhang Z., Yin D., Feng F., Ma J., POWDER TECHNOL, 367, 833 (2020)

21. Yao J., Yin Y., Zhao T., Ren W., Qiu Y., Guo W., Segmented enlarged-diameter borehole destressing mechanism and its influence on anchorage support system, ENERGY SCI ENG (2020)

22. Wang G., Liu Y., Xu J., INT J GEOMECH. 20:7, 4020094 (2020)

23. Hao X., Du W., Jiang Y., Tannant D., Zhao Y., Guo Y., ARAB J GEOSCI, 11:9 (2018)

24. Wang C., Shen B., Chen J., Tong W., Jiang Z., Liu Y., et al., GEOMECH ENG, 20:6, $485(2020)$

25. Fang Y., Xu C., Cui G, Kenneally B.. Scale model test of highway tunnel construction underlying mined-out thin coal seam. TUNN UNDERGR SP TECH, 56, 105 (2016)

26. Qu Q., Xu J., Wu R., Qin W., Hu G., INT J ROCK MECH MIN., 78, 91 (2015)

27. Liu Q., Chai J., Chen S., Zhang D., Yuan Q., Wang S., ENERGY SCI ENG. 8:6, 2011 (2020)

28. Chai J., Liu Q., Liu J., Zhang G., Zhang D., Qiu F., J SENSORS, 1 (2018)

29. Fan D., Liu X., Tan Y., Song S., Gu Q., Yan L., et al., ENERGIES, 12:10, 2032 (2019)

30. Du W., Jiang Y., Ma Z., Jiao Z., ARAB J GEOSCI, 10:21 (2017) 
31. Huang W., Wang X., Shen Y., Feng F., Wu K., Li C., ENERGY SCI ENG, 7:6, 2540 (2019)

32. Yang S., Chen M., Fang G., Wang Y., Meng B., Li Y., et al., TUNN UNDERGR SP TECH, 82, 248 (2018)

33. Ju M., Li X., Yao Q., Liu S., Liang S., Wang X., ENG GEOL, 226, 93 (2017)

34. Li S.C., Wang Q., Wang H.T., Jiang B., Wang D.C., Zhang B., et al., TUNN UNDERGR SP TECH. 47, 52 (2015)

35. Song S., Liu X., Tan Y., Fan D., Ma Q., Wang H., SHOCK VIB, 1 (2020)

36. Luo Z., Li D., Su B., Zhang S., Deng J., ENERGY, 198, 117329 (2020)

37. Zhang S., Shen B., Li Y., Zhou S., GEOFLUIDS, 1 (2019)

38. Li H., Deng J., Chen X., Shu C., Kuo C., Zhai X., et al., POWDER TECHNOL, 366, 294 (2020)

39. Meng Z., Shi X., Li G., ENG GEOL, 208, 69 (2016)

40. Xuan D., Xu J., Wang B., Teng H., ENG GEOL, 206, 71 (2016)

41. Sun X., Chen F., He M., Gong W., Xu H., Lu H, TUNN UNDERGR SP TECH., 63, 228 (2017)

42. Chai J., Liu Q., Liu J., Zhang D., OPT FIBER TECHNOL, 41, 40 (2018)

43. Wang T., Zhou Y., Luo Z., Wen H., Zhao J., Su B., et al., PROCESS SAF ENVIRON, 140, 178 (2020)

44. Li H., Deng J., Chen X., Shu C., Kuo C., Hu X., POWDER TECHNOL, 367, 860 (2020)

45. Shan P., Lai X., ENG COMPUTATION, 37:6, 2177 (2020)

46. Luo Z., Hao Q., Wang T., Li R., Cheng F., Deng J., FUEL, 259, 116295 (2020)

47. Liu R, Yu Y, Cheng W, Xu Q, Yang H, Shen J., GEOFLUIDS, 1 (2020)

48. Wen H., Cheng X., Chen J., Zhang C., Yu Z., Li Z., et al., PROCESS SAF ENVIRON, 136, 39 (2020)

49. Liu S., Liu W., PROCESSES. 6:11, 211 (2018)

50. Li H., Guo G., Zha J., ENVIRON EARTH SCI, 76:15 (2017)

51. Zha J., Li H., Guo G., Wang J., ENVIRON EARTH SCI, 76:21 (2017)

52. Wen C., Jia S., Fu X., Meng L., Zhao Z., ADV MATER SCI ENG, 2031276, 1 (2020)

53. Zhang S., Fan G., Zhang D., Chen M., Zhang C., ARAB J GEOSCI, 12:11 (2019)

54. Zhang G.C., Wen Z.J., Liang S.J., Tan Y.L., Tian L., Zhao Y.Q., et al., ROCK MECH ROCK ENG, 53:2, 497 (2020)

55. Zhao J., Zhang X., Jiang N., Yin L., Guo W., B ENG GEOL ENVIRON, 1 (2020)

56. Liu R., Cheng W., Yu Y., Xu Q., Jiang A., Lv T., SEM. PROCESS SAF ENVIRON, 122, 221 (2019)

57. Yang D., Guo W., Tan Y., ADV CIV ENG., 1 (2019)

58. Li G., Hu Y., Li Q., Yin T., Miao J., Yao M., , IEEE ACCESS. 8, 46701 (2020)

59. Zhao Z., Ma Q., Tan Y., Gao X., SIMULATION, 95:1, 83 (2018)

60. Lyu X., Zhao Z., Wang X., Wang W., GEOFLUIDS, UNSP, 8310128 (2019)

61. Jiang L., Wu Q., Wu Q., Wang P., Xue Y., Kong P., et al. ENG FAIL ANAL.; 98, 118 (2019) 
62. Chen S., Jiang T., Wang H., Feng F., Yin D., Li X., ENERGY SCI ENG. 7:6, 3020 (2019)

63. Chen L., Ma G., Liu G., Liu Z., CONSTR BUILD MATER. 225, 311 (2019)

64. Zhao J., Chen J., Zhan X., Ning J., Zhang Y., B ENG GEOL ENVIRON (2020)

65. Ouyang J., Chen X., Huangfu Z., Lu C., Huang D., Li Y., CONSTR BUILD MATER, 197, 778 (2019)

66. Liu G., Guo X., Cheng W., Chen L., Cui X., CONSTR BUILD MATER, 251, 119065 (2020)

67. Hu S., Tan Y., Zhou H., Ru W., Ning J., Wang J., et al., ENERGY SCI ENG, 8:3, 789 (2020)

68. Li Q., Li J., Zhang J., Wang C., Fang K., Liu L., et al., METALS-BASEL, 9:5, 606 (2019) 